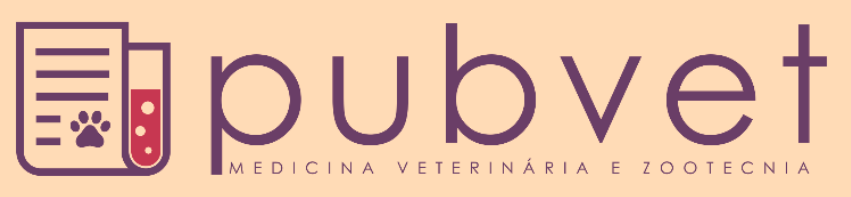

https://doi.org/10.31533/pubvet.v13n11a459.1-11

\title{
Analgesia farmacológica em pequenos animais
}

\author{
Rogério Romeu $^{1} \bullet$, Rochelle Gorczak ${ }^{2 *} \bullet$, Marilia Avila Valandro ${ }^{2} \bullet$ \\ ${ }^{I}$ Médico Veterinário Autônomo, Porto Alegre-RS, Brasil. \\ ${ }^{2}$ Professora do Centro Universitário Ritter dos Reis - UniRitter, Faculdade de Medicina Veterinária, Porto Alegre-RS, Brasil. \\ *Autor para correspondência, E-mail: rochellegorczak@gmail.com
}

Resumo. A dor é conhecida como o quinto sinal vital, e é de suma importância saber reconhecer seus sinais, uma vez que os animais não têm condições de verbalizar onde dói e como é esta dor. Classificá-la por meio de escalas de dor já disponíveis na medicina de pequenos animais, é essencial, para aí então, após mensurar e classificar esta dor, administrar um fármaco que possa gerar a analgesia. A dor pode ser classificada ainda, pelo tempo de duração, ou seja, aguda ou crônica, ou pela intensidade, fraca, moderada ou severa. As classes de fármacos mais utilizados para o controle da dor são as que possuem potencial analgésico, como os anti-inflamatório não esteroidais (AINES), opioides, corticosteroides, analgésicos antipiréticos, anestésicos locais, antagonista de receptores NMDA, miorrelaxantes, agonistas dos receptores $\alpha-2$ adrenérgicos, anticonvulsivantes e antidepressivos. A Associação de duas ou mais classes de fármacos chamados de multimodal, também é utilizada, para desta forma gerar uma sinergia entre os fármacos e assim provocar uma melhor analgesia. Esta revisão tem por objetivo abordar e esclarecer a farmacologia analgésica em pequenos animais. Uma analgesia bem realizada colabora para recuperação no pós-operatório, além de proporcionar maior conforto para os animais e desta forma reestabelecendo as liberdades que regem o bem-estar animal.

Palavras chave: AINE, anestesiologia, dor, nocicepção, opioides

\section{Pharmacological analgesia in small animals}

Abstract. Pain is known as the fifth vital sign, and it is extremely important to know how to recognize the signs of pain since animals cannot verbalize where it hurts and how painful it is. It is classified by means of pain scales already available in the veterinary medicine of small animals, it is essential, for then, after measuring and classifying this pain, administer a drug that can generate analgesia. Pain can be further classified by duration, acute or chronic, or by intensity, weak, moderate or severe. The most commonly used classes of drugs for pain control are those with analgesic potential, such as nonsteroidal antiinflammatory drugs (NSAIDs), opioids, corticosteroids, antipyretic analgesics, local anesthetics, NMDA receptor antagonists, myorelaxants, $\alpha$-receptor agonists -2-adrenergic agents, anticonvulsants and antidepressants. The association of two or more classes of drugs called multimodal is also used, in order to generate a synergy between the drugs and in this way to provoke a better analgesia. Well-made analgesia contributes to recovery in the postoperative period, besides providing greater comfort for the animals and thus reestablishing the freedoms that govern animal welfare.

Keywords: Anesthesiology, Nociception, NSAIDs, Opioids, Pain

\section{Analgesia farmacológica en pequeños animales}

Resumen. El dolor se conoce como el quinto signo vital, y es de suma importancia poder reconocer los signos del dolor ya que los animales no pueden verbalizar dónde duele y 
cómo es este dolor. Clasificarlo por escalas de dolor ya disponibles en la medicina de pequeños animales, es esencial, para después de medir y clasificar el dolor, administrar un medicamento que pueda generar analgesia. El dolor también se puede clasificar por su duración, es decir, aguda o crónica, o por su intensidad, débil, moderada o severa. Los fármacos para el control del dolor más utilizados son aquellos con potencial analgésico, como los antiinflamatorios no esteroideos (AINE), opioides, corticosteroides, analgésicos antipiréticos, anestésicos locales, antagonistas de los receptores NMDA, miorrelajantes, agonistas de los receptores $\alpha$. -2 adrenérgicos, anticonvulsivos y antidepresivos. La combinación de dos o más clases de medicamentos, llamadas multimodales, también se usa para generar sinergia entre los medicamentos y, por lo tanto, causar una mejor analgesia. Esta revisión tiene como objetivo abordar y aclarar la farmacología analgésica en animales pequeños. Una analgesia bien realizada contribuye a la recuperación después de la cirugía, además de proporcionar una mayor comodidad para los animales y, por lo tanto, restablecer las libertades que rigen el bienestar animal.

Palabras clave: AINE, anestesiología, dolor, nocicepción, opioides

\section{Introdução}

A definição clássica de dor, proposta e descrita pelo comitê de taxonomia da Associação Internacional para Estudo da Dor, na década de 70, diz que dor é uma percepção sensorial e emocional negativa relacionada a dano em tecidos (Tranquilli et al., 2013). Em 2016, foi proposta uma nova definição: "dor é uma experiência angustiante, associada a uma lesão tecidual atual ou potencial, com componentes sensoriais, emocionais, cognitivos e sociais" (Williams \& Craig, 2016).

Em seres humanos, há relatos de dor sem haver dano tecidual ou causa patológica e, nesses casos ocorre por motivação psicológica. Outro conceito importante é o de nocicepção, que é tido como o processo fisiológico neural de codificação, percepção e transmissão de estímulos nocivos que causam dor e, para isso, não é preciso que o paciente esteja consciente, ocorrendo mesmo durante o procedimento de anestesia geral (Tranquilli et al., 2013).

Analgesia, do grego ờ [an-], que significa "sem"; $\alpha$ $\lambda \gamma o s$ [álgos], que significa "dor", é a ausência de dor onde normalmente ocorre resposta a um estímulo doloroso (Williams \& Craig, 2016). As classes de fármacos mais utilizados para o controle da dor são as que possuem potencial analgésico, como os anti-inflamatórios não esteroidais (AINES), opioides, entre outros (Fantoni et al., 2002; Waran et al., 2010). Atualmente, a dor é considerada como o quinto sinal vital. Sua observação e classificação nos animais não é uma tarefa fácil, principalmente pela incapacidade de se comunicarem verbalmente. Devido a sua importância, a dor e seu controle são temas que estão sendo cada vez mais estudados (Tranquilli et al., 2013). Dessa forma, esse trabalho tem como objetivo realizar uma revisão de bibliografia acerca desse tema, enfatizando o controle da dor utilizando diferentes fármacos, sozinhos ou em associações, em cães e gatos.

\section{Dor: conceitos e classificação}

A dor é descrita como uma experiência multissensorial complexa que envolve aspectos sensoriais e emocionais é uma sensação e uma experiência desagradáveis, associadas a dano tecidual real ou potencial ou descritas em termos de tal dano. Ela é individual, sendo expressa e sentida de formas diferentes variando a intensidade de individuo para individuo (Williams \& Craig, 2016).

Nocicepção é o nome de que se dá ao processo neurológico de codificação dos estímulos nocivos cuja consequência pode ser uma ação comportamental ou uma ação autonômica tendo como exemplo da ação autonômica o aumento da pressão arterial, e exemplo da ação comportamental a retirada do membro de uma superfície quente (Tranquilli et al., 2013). A nocicepção pode ser dividida para efeitos de estudo em 4 etapas: transdução, transmissão, modulação e percepção. O estímulo nocivo ocorre e na transdução e é recebido pelos nociceptores e transformado em potencial de ação; na transmissão ele é transmitido dos nociceptores até o sistema nervoso periférico, no corno dorsal da medula espinhal o estímulo é modulado antes de chegar no sistema nervoso central, onde ocorre a percepção e interpretada como dor (Guyton \& Hall, 2011; Tranquilli et al., 2013). A dor pode ser classificada de várias formas, quanto a duração, intensidade, origem, entre outros fatores (Tranquilli et al., 2013). 
Em relação à duração, de forma bem simples, pode ser dividida em aguda e crônica (Janeiro, 2017; Tranquilli et al., 2013). A dor aguda ou dor rápida é aquela sentida em um intervalo de até 0,1 segundo após o estímulo doloroso. É geralmente conduzido por fibras nervosas do tipo $\mathrm{A} \delta$, de diâmetro médio, mielinizadas, modulando a primeira fase da dor semelhante a uma agulhada, não sendo sentida nas porções mais profundas. Essa é a sensação mais comum, tem uma duração curta e limitada, apresentando uma característica muito importante: sempre tem uma causa facilmente identificada, serve como um alerta que algum tecido está sendo estimulado e é muito utilizada como diagnóstico em várias patologias. Quando não identificada e tratada rapidamente, pode retardar a cicatrização de tecidos, aumentar o tempo de internação do paciente, causar sofrimento e se transformar em uma dor persistente (Fantoni et al., 2002; Janeiro, 2017). Pode durar de dias até semanas, e está ligada a procedimentos cirúrgicos, traumatismos, queimadura por calor, dor musculoesquelética, dor visceral ou pleural, e algumas condições clínicas, sendo, algumas vezes, auto limitante (Mazzaferro \& Ford, 2007; Tranquilli et al., 2013). Algumas dores agudas, se não tratadas corretamente, podem se transformar em dor crônica, como o caso das mastites (Tranquilli et al., 2013). Ainda, a dor aguda pode ser classificada segundo sua intensidade de leve a excruciante (torturante) (Mathews et al., 2015).

As dores crônicas ou lentas, geralmente estão ligadas a degeneração tecidual, como nas osteoartrites, doenças inflamatórias, neoplasias, dor musculoesqueléticas, distrofias simpáticas ou lesão neural (Mathews et al., 2015; Mazzaferro \& Ford, 2007; Tranquilli et al., 2013). Esse tipo de percepção é conduzido por fibras nervosas do tipo C, com velocidade mais lenta que as fibras do tipo A $\delta$. Esse tipo de dor usualmente é originado por um estímulo químico, mas também pode ser originado por estímulos físicos e térmicos. Por existir esta dupla inervação é que ocorre muitas vezes ocorre uma sensação de "dor dupla", uma dor inicial transmitida pelas fibras A $\delta$ seguida por uma dor latejante transmitida pelas fibras do tipo C, sendo, dessa forma, difícil localizar exatamente a dor crônica. Esse tipo de dor pode repercutir tanto na saúde física quanto mental nos pacientes, em alguns casos pode levar a perda da qualidade de vida, por isso, muitas vezes, ela pode ser encarada com uma doença em si e não somente um sinal clínico (Janeiro, 2017).

Em relação à origem, conforme tabela 1, a dor pode ser classificada como nociceptiva (dor fisiológica), inflamatória ou neuropática. A dor neoplásica tem características tanto da dor inflamatória como da dor neuropática (Mathews et al., 2015)

Tabela 1. Classificação de dor. Adaptado de Mathews et al. (2015)

\begin{tabular}{ll}
\hline Clasificação & Caracteristicas \\
\hline Inflamatória & $\begin{array}{l}\text { Início rápido e a duração e a intensidade estão diretamente associadas ao tamanho e tipo de lesão tecidual. } \\
\text { Neuropática }\end{array}$ \\
$\begin{array}{l}\text { Surge após um trauma ou lesão de nervos periféricos ou do sistema nervoso central } \\
\text { Nociceptiva }\end{array}$ & $\begin{array}{l}\text { Causada pela estimulação de receptores de dor como por exemplo as terminações nervosas encontradas na } \\
\text { pele }\end{array}$ \\
\hline
\end{tabular}

Ainda, conforme tabela 2, podemos ter mais uma classificação de dor em relação a sua origem, sendo elas mecânica, química ou térmica.

Tabela 2. Classificação de dor com base na origem. Adaptado de Mathews et al. (2015), McKune et al., 2015 e Hall, 2017.

\begin{tabular}{|c|c|}
\hline Clasificação & Caracteristicas \\
\hline Mecânica & Ocasionada pela excitação dos mecanoreceptores da pele como o caso dos traumas físicos. \\
\hline Química & $\begin{array}{l}\text { Causada por estímulos mediados por quimiorreceptores como o exemplo de inflamações que liberam } \\
\text { citocinas na corrente sanguínea }\end{array}$ \\
\hline Térmica & $\begin{array}{l}\text { Ocorre por estímulo nos termorreceptores da pele como o caso de queimaduras por frio e calor ocasionadas } \\
\text { na pele }\end{array}$ \\
\hline
\end{tabular}

\section{Quantificação da dor}

A quantificação da dor é uma tarefa muito importante, porém muito difícil visto que a dor envolve aspectos fisiológicos, emocionais e difere de animal para animal, espécie, raça e inclui intensidade, duração, frequência, além de ter que diferenciar alguns aspectos de dor de outras perturbações como medo, aflição e estresse (Mathews et al., 2014; Tranquilli et al., 2013)). 
A maioria dos estudos leva em conta, na quantificação da dor, parâmetros fisiológicos como frequência cardíaca (FC), frequência respiratória (FR), diâmetro de pupila, porém esses parâmetros, isoladamente, não são sinais patognomônico para dor. Existem fatores que podem influenciar esses parâmetros que não estão relacionados com dor, como estresse e medo. Esses parâmetros somados a outros indicadores multifatoriais, poderiam sim ajudar a mensurar a dor (Brown et al., 2008). Segundo Mazzaferro \& Ford (2007), a dor pode causar uma série de alterações fisiológicas no animal, assim como pode causar alterações em seu comportamento. Alguns exemplos de alterações fisiológicas são blefaroespasmo, bradicardia, bruxismo, arritmias cardíacas, hiperestesia, incontinência, midríase, respiração ofegante, ptialismo, taquicardia, taquipneia. Já em relação às alterações comportamentais, podemos citar foco na área de dor (lamber ou morder), inapetência, falta de auto higienização, micção e defecação anormais, estoicismo, agressão, bocejos, esconder-se, vocalização, lamúria ou chorar.

A mensuração da dor é um passo muito importante para determinar qual terapêutica utilizar e, desse modo, uma escala que possa ser utilizada em animais para classificá-la é tema de muitas pesquisas atualmente (Ferreira et al., 2015). A maior dificuldade ainda é identificar o que os pacientes sentem, onde está localizada a sensibilidade, há quanto tempo, se é uma dor que diminuiu ou aumenta, enfim a incapacidade dos pacientes veterinários verbalizar sobre a dor, é o maior motivo da criação de escalas de classificação de dor na medicina veterinária. Fatores importantes, como a mesma pessoa a avaliar o paciente em momentos diferentes, experiência com a condição dolorosa, idade, experiência clínica são fatores importantes para a avaliação. Atualmente temos poucas escalas de dor baseadas em comportamento de dor validadas para a medicina veterinária. Na dor aguda geralmente utiliza-se escalas de dor unidimensionais, apenas para avaliar a intensidade da dor (Tranquilli et al., 2013).

As escalas mais utilizadas são as que consideram respostas comportamentais e fisiológicas, ou seja, escalas multidimensionais, como a Escala de Dor da Universidade Estadual de São Paulo - UNESP a Escala Composta de Dor de Glasgow, sendo que ainda temos outras escalas de dor subjetivas e semi objetivas (Ferreira et al., 2015). A Escala Multidimensional da UNESP-Botucatu para avaliação de dor aguda em pós-operatórios de felinos é uma escala desenvolvida por pesquisadores brasileiros baseada em parâmetros comportamentais e parâmetros fisiológicos. É dividida em quatro sub-escalas sendo elas: Alteração Psicomotora, Proteção da Área Dolorosa, Variáveis Fisiológicas, Expressão Vocal da Dor. Esta escala apresenta uma maior acurácia, foi validada e apresentou eficácia no resgate analgésico quando utilizada por profissionais da medicina veterinária (Brondani et al., 2012).

Outras escalas (Figura 1) mais simples foram desenvolvidas. A Escala descritiva simples (EDS) é bastante simples e demasiadamente subjetiva, não apresenta sensibilidade em pequenas mudanças de intensidade de dor. A Escala numérica de gradação (ENG) utiliza números no lugar das descrições para graduar a dor. Geralmente é utilizada para dar um peso ao comportamento nas escalas multidimensionais. A Escala Visual Analógica (EVA) é uma escala que tem 100 milímetros onde o zero não há nenhuma dor e cem é a pior dor possível, após um procedimento. É necessário muito treinamento para que não haja divergências entre os avaliadores. Números intermediários escritos na escala ou descritores não são recomendados, pois podem induzir um resultado da avaliação. A Escala de Dor Aguda para Felinos desenvolvida pela Universidade do Estado do Colorado (Figura 2) é um exemplo de aplicação da EDS (Flôr et al., 2012; Tranquilli et al., 2013).

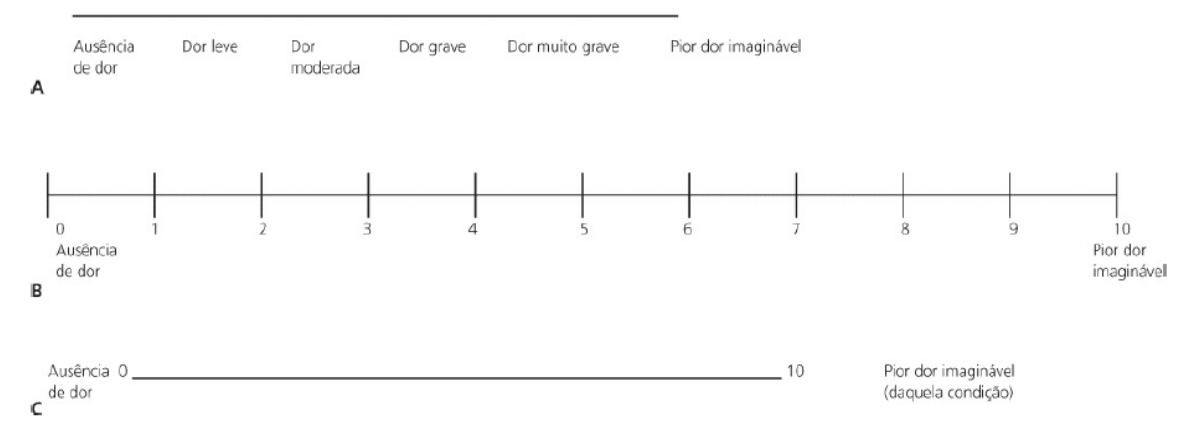

Figura 1. A. Escala descritiva Simples (EDS); B - Escala numérica de gradação (ENG); C Escala Visual Analógica (EVA). Fonte: Tranquilli et al. (2013). 
Em um estudo realizado com cães com osteoartrite, a aferição da pressão arterial não invasiva na base da cauda, mostrou ser um bom parâmetro para quantificação de dor nessa espécie (Brown et al., 2008). Em relação à biomarcadores, o cortisol plasmático e $\beta$-endorfinas não são bons marcadores quantitativos de dor, porém podem ser utilizados para categorizar a gravidade de uma doença (Tranquilli et al., 2013).

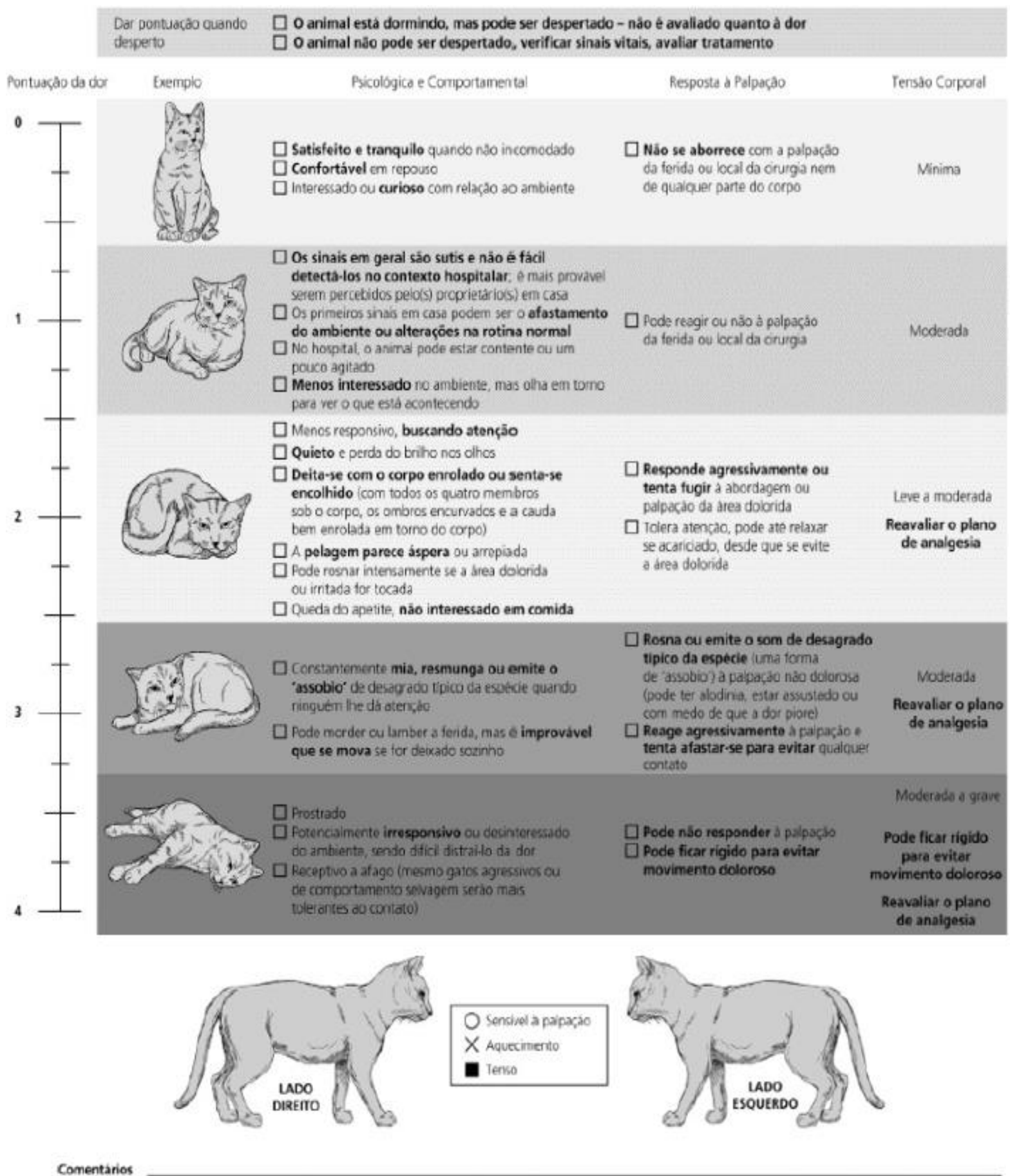

Figura 2. Escala de Dor Aguda para Felinos desenvolvida pela Universidade do Estado do Colorado. Fonte: McKune et al., 2015.

Outra forma de se determinar a dor é pelos níveis séricos de algumas substâncias mediadoras da dor. Bradicininas, interleucinas, prostaglandinas, substância P, calcitonina e citocinas são algumas delas. A aferição de cortisol e glicose são as mais comuns, em afecções ósseas pode se mensurar também Interleucina 6 (IL-6); porém, a forma de coleta e a espécie coletada podem influenciar nos resultados, 
pois a situação de estresse, principalmente em gatos, pode aumentar a concentração de cortisol na corrente sanguínea pelo estresse e não pela dor (Martins et al., 2010).

Pode-se classificar a dor segundo o procedimento realizado ou por patologia ou injúria que esse animal apresente. A tabela 3 apresenta a classificação de dor a partir da patologia/procedimento médico (Flôr et al., 2012).

Tabela 3. Classificação Patologia X Dor. Adaptado de Flôr et al. (2012).

\begin{tabular}{|c|c|}
\hline Leve a moderada & $\begin{array}{l}\text { Ovariohisterectomia em animais jovens, orquiectomia, nodulectomia, procedimentos cirúrgicos } \\
\text { oftálmicos, procedimentos dentários simples, algumas lacerações, cistites, otites, toracocentese. }\end{array}$ \\
\hline Moderada & $\begin{array}{l}\text { Reparo articular extracapsular, procedimentos ortopédicos pouco invasivos, laparotomia (não } \\
\text { inflamada), herniorrafia inguinal, herniorrafia diafragmática (aguda, sem injúria de órgão), } \\
\text { nodulectomia (dependendo da localização, do tamanho e do envolvimento de estruturas), } \\
\text { pancreatite em resolução, injúria de tecidos moles, obstrução uretral, ovariohisterectomia (animais } \\
\text { idosos e obesos), orquiectomia, procedimentos odontológicos, enucleação. }\end{array}$ \\
\hline Moderada a intensa e intensa & $\begin{array}{l}\text { Osteoartrite, poliartrite aguda, procedimento cirúrgico intra-articular, reparação de fratura, } \\
\text { amputação de membro, estágios de resolução de algumas injúrias de tecidos moles, inflamação ou } \\
\text { doenças, peritonite, pleurite, dor capsular como resultado de organomegalia (pielonefrite, hepatite, } \\
\text { esplenite, torção esplênica), distensão de órgão cavitário, torção mesentérica, gástrica, testicular, } \\
\text { obstrução de uretra, ureter e biliar, toracotomia, laparatomia, oniectomia, herniorrafia } \\
\text { diafragmática (associada a extensão da lesão de tecidos), politraumatismo, doença de disco } \\
\text { toracolombar, ablação total de canal auditivo, reaquecimento após hipotermia acidental, } \\
\text { congelamento, dor oncológica, mucosite após terapia de radiação, trombose ou isquemia (arterial } \\
\text { ou venosa) trombose aórtica, osteodistrofia hipertrófica, panosteíte,ulceração ou abrasão corneal, } \\
\text { glaucoma e uveíte, mastite. }\end{array}$ \\
\hline tensa o & $\begin{array}{l}\text { Dor neuropática, incluindo encarceramento de nervo, herniação de disco intervertebral cervical e } \\
\text { inflamação extensa, dor pós-operatória quando a lesão tecidual é extensa ou existe inflamação, } \\
\text { reparação de múltiplas fraturas quando há injuria tecidual de tecidos moles ou pinçamento por } \\
\text { implante ortopédico em tecido neuronal, pancreatite e cistite necrosante, fratura patológica, } \\
\text { neoplasia óssea (especialmente após biópsia), meningite. }\end{array}$ \\
\hline
\end{tabular}

\section{Tratamento da dor}

Os fármacos desempenham um papel fundamental no tratamento da dor, e em geral são utilizados como primeira escolha. As classes de fármacos mais utilizados para o controle da dor são as que possuem potencial analgésico, como os anti-inflamatórios não esteroidais (AINES), corticosteroides, analgésicos antipiréticos, anestésicos locais, antagonista de receptores NMDA, agonistas dos receptores $\alpha-2$ adrenérgicos, anticonvulsivantes e, principalmente, opioides (Fantoni et al., 2002; Tranquilli et al., 2013).

\section{Anti-inflamatórios não esteroidais (AINES)}

Os AINES são muito utilizados na medicina veterinária, pois além de combater a inflamação, proporciona uma analgesia. O mecanismo de ação dos AINES ocorre pela inibição da cadeia do ácido araquidônico evitando a formação de prostanoides. O Ácido Araquidônico é um ácido graxo constituinte da membrana celular e uma boa parte dele é reutilizada pelas membranas celulares, porém outra parte pode sofrer os efeitos da enzima Ciclo-Oxigenase (COX) que resultam em eicosanoides, substâncias mediadoras que são utilizadas na homeostasia e doença. Alguns desses eicosanoides, por sua vez, são metabolizados por prostaglandinas, prostaciclinas e tromboxanos que depois dão origem a reações inflamatórias e imunológicas (Tasaka, 2017). As enzimas COX são divididas em COX-1, COX-2, COX3 , sendo que a COX-1 e estão presentes em vários tecidos como estômago, intestinos, rins e plaquetas. No estômago, ela está relacionada com a proteção gástrica e é conhecida como uma enzima fisiológica. Já a COX-2 é considerada uma enzima patológica, dessa forma, está associada a geração de inflamação e dor. Por fim, a COX-3 é considerada uma variante da COX-1 (Tasaka, 2017; Tranquilli et al., 2013).

Em geral, o pico de ação analgésica dos AINEs ocorre em média de 30 a 60 minutos após a administração, sendo mais eficiente para dor somática do que para dor visceral. Os efeitos negativos do uso de AINE, na maioria dos casos, são lesões gástricas, renais e hepáticas. Houve muitas pesquisas para o desenvolvimento de um fármaco que fosse seletivo somente para COX-2, e delas surgiram os "Coxibes" uma classe de AINE seletiva para COX-2. O primeiro medicamento dessa classe 
desenvolvido para medicina veterinária foi o deracoxibe seguido posteriormente pelo firocoxibe e robenacoxibe (Tranquilli et al., 2013).

A escolha do AINE é um fator muito importante e deve-se levar em consideração a espécie que receberá o medicamento, pois em alguns casos os AINEs recomendados para cães, não são recomendados para gatos (Tabela 4) (Górniak, 2012).

Tabela 4. AINEs recomendados para cães e gatos. Adaptado de Górniak (2012).

\begin{tabular}{ll}
\hline \multirow{2}{*}{ Recomendado para cães } & $\begin{array}{l}\text { Carprofeno, Etodolaco, Meloxicam, Cetoprofeno, Deracoxibe, Firocoxibe, Ácido } \\
\text { meclofenâmico, Robenacoxibe, Tepoxalina, Ácido tolfenâmico, Mavacoxibe, Cimicoxibe, } \\
\text { Piroxicam, Dipirona }\end{array}$ \\
\hline Recomendado para gatos & Meloxicam, Carprofeno, Robenacoxibe, Cetoprofeno, Ácido tolfenâmico, Dipirona \\
\hline
\end{tabular}

O Carprofeno, um fármaco com um potencial analgésico muito grande, vem sendo recomendado em cães para trans-cirúrgico e pós-cirúrgico, e em pesquisas realizadas mostrou-se mais eficiente que medicamentos como mepedirina e butorfanol sendo, nesses casos, administrados no pré-operatório. Ele estimula a produção de glicosaminoglicanos e possui baixa ação antitromboxana (Tasaka, 2017). Já o cetoprofeno é um fármaco que pode ser utilizado em cães e gatos com potencial analgésico para dores agudas de leve a moderada. Seu potencial analgésico se mostrou superior ou com tempo de ação superior a opioides como mepedirina, oximorfona, buprenorfina e butorfanol. É um fármaco mais seguro que o carprofeno, porém ainda mostra possibilidades de produzir ulcerações gastrointestinais (Górniak, 2012; Tasaka, 2017).

Por sua vez, a dipirona é um AINE que tem uma boa capacidade analgésica principalmente para dor visceral, tem uma ação antitérmica muito boa, porém não atua como anti-inflamatório. Seus efeitos colaterais são baixos, não sendo nefrotóxico ou hepatotóxico. Quando associado a outros fármacos produz uma potencialização analgésica e uma melhor antinocicepção (Mencalha et al., 2019; Tasaka, 2017). Um dos fármacos com maior utilização na clínica de pequenos animais é o meloxicam, inibidor seletivo da COX2, muito empregado nas dores crônicas em cães e gatos, principalmente em sistema músculoesqueléticos e tecidos moles. Em estudos já foram identificadas erosões gástricas quando se faz o uso crônico desse medicamento em cães, porém apresenta baixo impacto nefrotóxico ou hepatotóxico (Górniak, 2012; Tasaka, 2017). Em gatos, a dose de 0,01 a 0,03 mg/kg a cada 24 horas pode ser utilizada por vários meses em pacientes com doenças crônicas degenerativas (Mencalha et al., 2019). Na classe dos AINEs COX-2 seletivos, o firocoxibe é relativamente novo no mercado, ainda não muito estudado, porém tem sido muito utilizado em animais com osteoartrites (Górniak, 2012).

\section{Corticoides}

Os glicocorticoides ou corticoides (CC), são hormônios produzidos pelo próprio organismo, desempenhando várias funções fisiológicas. Dependendo da espécie, pode ser a corticosterona ou o cortisol que é produzido pelas glândulas adrenais. Apresentam ações anti-inflamatórias, imunossupressoras e efeitos cardiológicos. Nos CC sintéticos, criados em meados dos anos 1950, foi potencializada as ações imunossupressoras e anti-inflamatórias e minimizados os efeitos mineralocorticoides (Górniak, 2012). A ação analgésica no uso crônico de CC está associada com o potencial de alteração da expressão dos neuropeptídios envolvidos com a transmissão nociceptiva na medula, desempenhando um papel muito importante na mediação da dor. O fármaco CC mais utilizado na analgesia na medicina veterinária é a prednisona, um CC sintético com ação anti-inflamatória, apresenta, também, propriedade antitumoral e discreta atividade mineralocorticoide, diminui a migração de leucócitos e a permeabilidade capilar, é metabolizado no fígado transformado em prednisolona que se liga a um receptor no núcleo celular que estimula a RNA polimerase a produzir uma proteína que inibe a fosfolipase A2 que, por sua vez, interrompe a síntese de prostaglandinas e, dessa forma, a inflamação (Górniak, 2012; Jericó et al., 2015).

\section{Anestésicos locais}

Os anestésicos locais são fármacos que bloqueiam a sinapse nervosa quando aplicados em uma região, com a vantagem de possuir efeito reversível sem lesões em nenhum tecido e efeitos adversos são raros, além de agir somente no local aplicado, não havendo impacto em outros sistemas. Quando aplicado no tronco 
nervoso, ele bloqueia as fibras sensitivas e motoras da região (Cartopassi \& Junior, 2012). Dentro dessa classe podemos destacar os seguintes fármacos maus utilizados na medicina veterinária: lidocaína, que é um fármaco com um período de latência com tempo de ação de até 120 minutos, e quando associada com adrenalina ela pode ter um período de duração anestésica de mais 60 minutos, e sua dose tóxica para cães é de 6 a $10 \mathrm{mg} / \mathrm{kg}$ na anestesia infiltrativa; a bupivacaina, por sua vez, é um fármaco que possui um período de latência maior, de 30 a 480 minutos porém com tempo de ação de até 5 horas, possui uma toxidade 40 vezes maior que a lidocaína e sua dose não pode ultrapassar $2 \mathrm{mg} / \mathrm{kg}$; por fim, a ropivacaina é um fármaco que possui uma latência de 20 minutos e tempo de ação de até 8 horas, possui efeitos secundários menores do que a bupivacaina, e a dose indicada a cães para via peridural é de 1 a 3 mg/kg (Cartopassi \& Junior, 2012; Mathews et al., 2014).

\section{Antagonistas NMDA}

Os antagonistas de receptores NMDA (N-metil D-Aspartato) são uma classe de analgésicos/anestésicos que tem como ação a inibição da ativação de receptores NMDA. Estes receptores são ativados pelo glutamato ou pela glicina, dessa forma, ativando uma via neural no cérebro responsável pela dor, memória e alerta. Eles agem com um íon de $\mathrm{Mg}$ bloqueando os canais iônicos impedindo a passagem do $\mathrm{Na}^{+} \mathrm{e} \mathrm{Ca}^{+}$que ativam o neurônio, logo, esse fármaco tem como objetivo evitar a sensibilização central (Aleixo \& Tudury, 2007; Aleixo et al., 2017). O Principal fármaco dessa classe utilizado na medicina veterinária é a Cetamina, que como analgésico é utilizada em micro-doses. Nessas doses quase nunca é observado efeitos secundários indesejáveis. Já na administração por via oral, temos os fármacos amantadina e dextrometorfano (Lamont, 2008).

Segundo Muir \& Gaynor (2009) a infusão continua de morfina, lidocaína e cetamina (MLK), proporciona um efeito analgésico adequado para procedimentos cirúrgicos cruentos e sua administração não está associada a distúrbios hemodinâmicos desfavoráveis. Em estudos, a concentração alveolar mínima (CAM) do isofluorano foi reduzida em $45 \%$ quando usado MLK, na seguinte dose: morfina (3,3 $\mu \mathrm{g} / \mathrm{kg} / \mathrm{min})$, lidocaína (50 $\mu \mathrm{g} / \mathrm{kg} / \mathrm{min})$ e cetamina $(10 \mu \mathrm{g} / \mathrm{kg} / \mathrm{min})$.

Outros estudos demonstraram que uma subdose de cetamina previne a sensibilização no sistema nervoso central, desta forma, atua bloqueando o fenômeno de potencialização da dor. As subdoses são suficientes para bloquear os receptores NMDA de modo a promover insensibilização de neurônios na medula espinhal reduzindo o reflexo nociceptivos. Nesse caso a cetamina associada a um opioide tem seu efeito analgésico potencializado, se comparado à utilização destes dois fármacos de formas isoladas. Na infusão contínua em procedimentos cirúrgicos, pode ser utilizado no pré-operatório de $0,5 \mathrm{mg} / \mathrm{kg}$, do fármaco em bolus, seguido de infusão na taxa de $10 \mu \mathrm{g} / \mathrm{kg} / \mathrm{min}$ durante o procedimento até o término da estimulação, podendo manter durante 24 horas após a cirurgia infusão mais baixa de $2 \mu \mathrm{g} / \mathrm{kg} / \mathrm{min}$ (Bianchi, 2010).

\section{Agonistas dos receptores $\alpha-2$ adrenérgicos}

Os receptores adrenérgicos estão localizados difundidos pelo sistema nervoso central e possuem estreita proximidade com os receptores opioides, assim, essas classes de fármacos usadas em associação são altamente sinérgicas para sedação e analgesia. Deve-se ter em mente que os efeitos colaterais cardiovasculares ocorrem mesmo em dosagens baixas (Mencalha et al., 2019; Oleskovicz \& Corrêa, 2012). Nessa classe, destacam-se a dexmedetomidina, a medetomidina e a detomidina. Seu uso está associado a efeitos analgésicos centrais, no entanto, seu uso se restringe a hospitais devido à formulação exclusiva injetável (Mencalha et al., 2019; Spinosa et al., 2002).

\section{Anticonvulsivantes}

A gabapentina e a pregabalina são fármacos semelhantes estruturalmente ao do ácido $\gamma$ aminobutírico (GABA), porém não utilizam esse receptor para proporcionar analgesia. Seu uso está mais indicado para dores crônicas e dores neuropáticas e seus mecanismos de ação para provocar analgesia ainda não estão totalmente descritos. Aparentemente, agem na inibição dos canais de cálcio neuronais dependentes de voltagem do tipo $\mathrm{N}$ que leva influxo de cálcio nos neurônios, inibindo a liberação de uma série de neurotransmissores, estimulando o movimento dos canais para longe da membrana celular dos neurônios provocando desta forma analgesia. A gabapentina é o fármaco dessa classe mais utilizado na dose de 10 a 15mg/kg, VO, a cada 12-24 horas (Kaminishi \& Hirano, 2017; 
Martins \& Souto, 2012). É uma excelente opção terapêutica para gatos com dores neuropáticas, crônicas ou agudas, na dose de 3 a $5 \mathrm{mg} / \mathrm{kg}$ a cada 12 horas, podendo chegar a $10 \mathrm{mg} / \mathrm{kg}$ se necessário (Mencalha et al., 2019). Já os dados farmacocinéticos para uso da pregabalina para analgesia em cães, sugerem que as concentrações plasmáticas associadas com analgesia em seres humanos são alcançadas com $4 \mathrm{mg} / \mathrm{kg}$ VO, e seu uso clínico como analgésico nessa espécie continua informal (Tranquilli et al., 2013).

\section{Opioides}

Os opiáceos são fármacos derivados do ópio, uma papoula (Papaver somniferum), já o opioide é qualquer substância que interaja com receptores opioides. Essa classe de medicamentos durante muitos anos foi ignorada pelos médicos veterinários em decorrência de seus efeitos colaterais, principalmente em felinos. Foram identificados e classificados três tipos de receptores opioides: mu $(\mu)$, kappa $(\kappa)$ e delta $(\delta)$. Seus efeitos ocorrem por ligações desses receptores localizados no sistema nervoso central (SNC) e outros lugares, e a diferença da afinidade nesses receptores explica a diferença entre os fármacos opioides conhecidos. A potência de um fármaco dessa classe é determinada pela dose necessária para produzir um efeito analgésico, como por exemplo, a fentanila (dose de $0,01 \mathrm{mg} / \mathrm{kg}$ ) e a morfina (dose de $1 \mathrm{mg} / \mathrm{kg}$ ), onde a fentanila é considerada mais potente que a morfina, pois necessita de uma quantidade muito menor de fármaco para se atingir o efeito desejado (Górniak, 2017). O receptor $\delta$ parece estar associado no efeito emético, enquanto os receptores $\mu$ e $\kappa$ podem estar relacionados nos efeitos antieméticos (Fantoni et al., 2002; Górniak, 2017).

Devido à extensa localização dos receptores opioides, em todo o corpo do animal, podem ser constatados efeitos em todo o organismo quando administrado um fármaco dessa classe. A presença da dor pode diminuir defeitos adversos indesejáveis nos animais, como a ocorrência de vômitos e disforia em animais hígidos, porém a mesma dose pode não apresentar esses efeitos se administrado em um animal com dor. De maneira geral os opioides causam depressão respiratória mediada por receptores opioides $\mu$ supraespinais, porém nos animais, na maioria dos casos, atinge um patamar inferior, onde não é necessária nenhuma intervenção (Mencalha et al., 2019).

Dentre os opioides mais utilizados na medicina veterinária, a morfina é amplamente utilizada hoje em dia em razão do seu custo benefício. É praticamente um agonista opioide $\mu$ completo cuja meia-vida ocorre após 1 hora após a administração. Em cães com dose de 0,5 e $1 \mathrm{mg} / \mathrm{kg}$ por via intravenosa (IV), foi observado a liberação de histaminas, devido à essa observação, deve ser utilizado com cautela em pacientes com mastocitomas, sendo indicado a administração na dose 0,2 a $0,5 \mathrm{mg} / \mathrm{kg}$ intramuscular (IM). Não é recomendada a administração deste fármaco por via oral em animais (Górniak, 2012; Tranquilli et al., 2013).

A metadona é um agonista de receptores $\mu$ e possui também outros mecanismos como a inibição da recaptação de monoaminas e a ação antagonista em receptores N-metil-D-aspartato (NMDA), sendo muito utilizado no peri-operatório e em caso de dores crônicas (Górniak, 2017; Mencalha et al., 2019). Em animais tem duração média de 4 horas, sendo indicados nas mesmas doses da morfina, podendo ser administrado IV ou IM. Não é recomendada a administração por via oral. Além delas, o fentanil, fármaco do tipo agonista opioide $\mu$ completo altamente potente, é muito utilizado em infusão continua no transoperatório. Em infusões com tempo superior a 2 horas pode aumentar o período de recuperação anestésica. Pode causar bradicardia pela estimulação vagal e hipotensão, porém com boa resposta a anticolinérgicos. Possui apresentação em adesivos transdérmicos que tem efeito analgésico de até 72 (Fantoni et al., 2002; Tranquilli et al., 2013).

O remifentanil, por sua vez é um medicamento de ultracurta duração com pico analgésico chegando aos 5 minutos. É muito utilizado em infusão continua no transoperatório pois desta forma ele propõe analgesia e ainda pode reduzir o CAM do isufluorano em até $60 \%$ em cães com uma dose de 0,15 a 0,3 $\mu \mathrm{g} / \mathrm{kg} / \mathrm{min}$, doses maiores não causam essa redução. Quando utilizado em infusão contínua no transoperatório deve-se, antes do final da infusão, administrar outro analgésico para o pós-operatório. Já a mepedirina ou petidina, uma droga menos potente, produz analgesia de leve a moderada e menos sedação que a morfina, pode bloquear canais se sódio e agir de forma parecida com os anestésicos locais. Seu efeito analgésico pode durar ao máximo de 3 horas. Não deve ser utilizada por via IV pois também pode causar liberação de histaminas, sendo indicado na dose 2 a $3 \mathrm{mg} / \mathrm{kg}$ IM. Como medicação préanestésica apresenta a vantagem de não provocar êmese e é um dos fármacos mais assertivos no controle dos tremores pós-operatórios (Górniak, 2017; Tranquilli et al., 2013). 
O tramadol é um análogo sintético da codeína classificado como opioide atípico e seu mecanismo de ação transita entre uma fraca ação em receptores $\mu$ e ação monoaminérgica por inibição da captação de norepinefrina e serotonina. É indicado para dores leves a moderadas, sendo utilizado e associação a fármacos de outras classes analgésicas para todos os tipos de dor. Sua grande vantagem é a possibilidade da utilização por via oral (Mencalha et al., 2019; Tranquilli et al., 2013).

O butorfanol é um fármaco opioide agonista de receptores e antagonistas com receptores $\mu$. Causa poucas alterações cardiovasculares e baixa depressão respiratória. Tem uma ação melhor para analgesia visceral e uma baixa eficácia para dor somática. Não é recomendado para dores severas pois possui um efeito teto e também não é recomendado seu uso concomitante com outros opioides agonistas de receptor $\mu$. Tem uma ação de até 90 minutos em gatos e até 3 horas em cães (Fantoni \& Cortopassi, 2009).

Ainda, há a buprenorfina, um agonista de receptores $\mu 25$ vezes mais potente que a morfina. Seus efeitos são semelhantes, porém pode ser mais efetiva para dores crônicas e em gatos pode produzir menos efeitos colaterais. Seu pico de efeito ocorre aos 90 minutos e o tempo de duração da analgesia pode ser de até 8 horas, chegando a 12 horas dependendo da dose e existem adesivos transdérmicos, com efeito, de até 96 horas. Foi aprovada uma formulação pelo FDA que em uma única dose subcutânea proporciona analgesia por até três dias (Tranquilli et al., 2013).

\section{Conclusão}

O conhecimento de todas as classes de fármacos com potencial analgésico, bem como seu mecanismo de ação e efeitos adversos, é muito importante para que o médico veterinário saiba qual protocolo utilizar naquele paciente de forma individualizada. A Associação de duas ou mais classes de fármacos muitas vezes pelo poder de sinergismo proporciona uma analgesia melhor e frecuentemente por mais tempo, aumentando o intervalo de doses. Outro ponto importante é a mensuração da dor, antes e depois do resgate analgésico, para dessa forma identificar se a técnica ou fármaco analgésico está sendo efetiva para o tratamento em questão.

\section{Referências bibliográficas}

Aleixo, G. A. S. \& Tudury, E. A. (2007). Utilização de opióides na analgesia de cães e gatos. Veterinária Notícias, 11(2):31-42.

Aleixo, G. A. S., Tudury, E. A., Coelho, M. C. O. C., Andrade, L. S. S. \& Bessa, A. L. N. G. (2017). Tratamento da dor em pequenos animais: classificação, indicações e vias de administração dos analgésicos (revisão de literatura: parte II). Medicina Veterinária, 11(1):29-40.

Bianchi, S. P. (2010). Uso da cetamina como analgésicos em cães e gatos. Monografia (Graduação). Universidade Federal do Rio Grande do Sul, Faculdade de Veterinária, Porto Alegre, Brasil.

Brondani, J. T., Luna, S. P. L., Minto, B. W., Santos, B. P. R., Beier, S. L., Matsubara, L. M. \& Padovani, C. R. (2012). Validity and responsiveness of a multidimensional composite scale to assess postoperative pain in cats. Arquivo Brasileiro de Medicina Veterinária e Zootecnia, 64(6):1529-1538.

Brown, D. C., Boston, R. C., Coyne, J. C. \& Farrar, J. T. (2008). Ability of the canine brief pain inventory to detect response to treatment in dogs with osteoarthritis. Journal of the American Veterinary Medical Association, 233(8):1278-1283.

Cartopassi, S. R. G. \& Junior, E. M. (2012). Anestésicos locais. In D. T. Fantoni (Ed.), Tratamento da dor na clínica de pequenos animais. Rio de Janeiro, Brasil: Elsevier.

Fantoni, D. T. \& Cortopassi, S. R. G. (2009). Anestesia em cães e gatos. São Paulo:, Brasil: Roca.

Fantoni, D. T., Mastrocinque, S., Fantoni, D. T. \& Cottopassi, S. R. (2002). Fisiopatologia e controle da dor. In D. T. Fabntoni (Ed.), Anestesia em cães e gatos (pp. 323-336). São Paulo: Roca.

Ferreira, L. F. L., Braccini, P. \& Franklin, N. (2015). Escala de dor em pequenos animais-revisão de literatura. PUBVET, Art. 1651(1-8):0001-0083.

Flôr, P. B., Martins, T. L. \& Yazbek, K. V. B. (2012). Avaliação da dor. In D. T. Fantoni (Ed.), Tratamento da dor na clínica de pequenos animais. Rio de Janeiro, Brasil: Elsevier.

Górniak, S. L. (2012). Anti-inflamatórios não esteroidais. In D. T. Fantoni (Ed.), Tratamento da dor na clínica de pequenos animais. Rio de Janeiro, Brasil: Elsevier. 
Górniak, S. L. (2017). Hipnoanalgésicos. In H. S. Spinosa, S. L. Górniak \& M. M. Bernardi (Eds.), Farmacologia aplicada à medicina veterinária. Rio de Janeiro, Brasil.: Guanabara Koogan.

Guyton, A. C. \& Hall, J. E. (2011). Tratado de fisiologia médica: Elsevier Brasil.

Hall, J.E. (2017). Dor, cefaleia e sensações térmicas. In.: Hall, J.E. (ed.) Guyton \& Hall Tratado de Fisiologia Médica (13 ${ }^{\mathrm{a}}$ ed.). Elsevier, Rio de Janeiro, Brasil.

Janeiro, M. I. (2017). Fisiologia da dor. Master of Science, Universidade Lusófona de Humanidades e Tecnologias, Lisboa, Portugal.

Jericó, M. M., Kogika, M. M. \& Andrade Neto, J. P. (2015). Tratado de medicina interna de cães e gatos. Rio de Janeiro, Brasil: Guanabara Koogan.

Kaminishi, Á. P. S. \& Hirano, L. Q. L. (2017). Uso de gabapentina no controle da dor em pequenos animais: revisão de literatura. Revista Veterinária em Foco, 14(2):29-35.

Lamont, L. A. (2008). Adjunctive analgesic therapy in veterinary medicine. Veterinary Clinics of North America: Small Animal Practice, 38(6):1187-1203.

Martins, T. L., Kahvegian, M. A. P., Noel-Morgan, J., Leon-Román, M. A., Otsuki, D. A. \& Fantoni, D. T. (2010). Comparison of the effects of tramadol, codeine, and ketoprofen alone or in combination on postoperative pain and on concentrations of blood glucose, serum cortisol, and serum interleukin-6 in dogs undergoing maxillectomy or mandibulectomy. American Journal of Veterinary Research, 71(9):1019-1026.

Martins, T. L. \& Souto, M. T. (2012). Antidepressivos e anticonvulsivantes. In D. T. Fantoni (Ed.), Tratamento da dor na clínica de pequenos animais. Rio de Janeiro, Brasil: Elsevier.

Mathews, K., Kronen, P. W., Lascelles, D., Nolan, A., Robertson, S., Steagall, P. V. \& Yamashita, K. (2015). Guidelines for recognition, assessment and treatment of pain. The Veterinary Nurse, 6(3):164-173.

Mathews, K., Kronen, P. W., Lascelles, D., Nolan, A., Robertson, S., Steagall, P. V. M., . . Yamashita, K. (2014). Guidelines for recognition, assessment and treatment of pain: WSAVA Global Pain Council members and co-authors of this document. Journal of Small Animal Practice, 55(6):E10-E68.

Mazzaferro, E. M. \& Ford, R. B. (2007). Dor: avaliação, prevenção e controle. In R. B. Ford \& E. M. Mazzaferro (Eds.), Manual de procedimentos veterinários e tratamento emergencial. Rio de Janeiro, Brasil: Saunders.

McKune, C. M., Murrel, J. C., Nolan, A. M., White, K. L. \& Whight, B. D. (2015). Nocicepção e dor. In. Tranquilli, W. J., Thurmon, J. C. \& Grimm, K. A. (eds.) Lumb \& Jones Anestesiologia e analgesia veterinária ( $5^{\mathrm{a}}$ ed.). Roca, São Paulo, Brasil.

Mencalha, R., Pereira, M. A. A. \& Souza, D. S. (2019). Intervenções farmacológicas em dor crônica. In R. Mencalha (Ed.), Abordagem clínica da dor crônica em cães e gatos: identificação e tratamento. Curitiba, Paraná, Brasil: MedVep.

Muir, W. W. \& Gaynor, J. S. (2009). Manual de controle da dor em medicina veterinária (Vol. 1). São Paulo, Brasil: MedVet.

Oleskovicz, N. \& Corrêa, A. L. (2012). a2-agonistas no controle da dor. In D. T. Fantoni (Ed.), Tratamento da dor na clínica de pequenos animais. Rio de Janeiro, Brasil.: Elsevier.

Spinosa, H. S., Górniak, S. L. \& Bernardi, M. M. (2002). Farmacologia aplicada à medicina veterinária. Rio de Janeiro: Guanabara Koogan.

Tasaka, A. C. (2017). Anti-inflamatórios não esteroidais. In H. S. Spinosa, S. L. Górniak \& M. M. Bernardi (Eds.), Farmacologia aplicada à medicina veterinária. Rio de Janeiro, Brasil: Guanabara Koogan.

Tranquilli, W. J., Thurmon, J. C. \& Grimm, K. A. (2013). Lumb and Jones' veterinary anesthesia and analgesia. Iowa, USA: John Wiley \& Sons.

Waran, N., Williams, V. M., Clarke, N. \& Bridge, I. S. (2010). Recognition of pain and use of analgesia in horses by veterinarians in New Zealand. New Zealand Veterinary Journal, 58(6):274-280.

Williams, A. C. C. \& Craig, K. D. (2016). Updating the definition of pain. Pain, 157(11):2420-2423.

Recebido: 22 de agosto, 2019.

Aprovado: 5 de outubro, 2019.

Publicado: 21 de dezembro, 2019.
Licenciamento: Este artigo é publicado na modalidade acesso aberto sob a licença Creative Commons Atribuição 4.0 (CC-BY 4.0), a qual permite uso irrestrito, distribuição, reprodução em qualquer meio, desde que o autor e a fonte sejam devidamente creditados. 